Editorial

\title{
Sustainable Energy Consumption
}

\author{
Carlos Ramos ${ }^{1, *(\mathbb{D}}$, Zita Vale ${ }^{1, *(\mathbb{D})}$, Peter Palensky ${ }^{2}\left(\mathbb{D}\right.$ and Hiroaki Nishi ${ }^{3}{ }^{(\mathbb{D}}$ \\ 1 GECAD—Research Group on Intelligent Engineering and Computing for Advanced Innovation \\ and Development, Institute of Engineering-Polytechnic of Porto, Rua Dr. Antonio Bernardino de Almeida, \\ 431, 4200-072 Porto, Portugal \\ 2 Intelligent Electrical Power Grids, Faculty of Electrical Engineering, Mathematics and Computer Science, \\ Technische Universiteit Delft (TU Delft), 2628 CD Delft, The Netherlands; P.Palensky@tudelft.nl \\ 3 Department of System Design Engineering, Faculty of Science and Technology, Keio University, \\ Yokohama 223-8522, Kanagawa, Japan; west@keio.jp \\ * Correspondence: csr@dei.isep.ipp.pt (C.R.); zav@isep.ipp.pt (Z.V.)
}

Citation: Ramos, C.; Vale, Z.; Palensky, P.; Nishi, H. Sustainable Energy Consumption. Energies 2021, 14, 6665. https://doi.org/10.3390/ en14206665

Received: 13 December 2020

Accepted: 12 October 2021

Published: 14 October 2021

Publisher's Note: MDPI stays neutral with regard to jurisdictional claims in published maps and institutional affiliations.

Copyright: (c) 2021 by the authors. Licensee MDPI, Basel, Switzerland. This article is an open access article distributed under the terms and conditions of the Creative Commons Attribution (CC BY) license (https:// creativecommons.org/licenses/by/ $4.0 /)$.
Energy use in homes and buildings represents an important part of the load of electrical systems. Maintaining a comfortable level in the indoor environment, namely, for heating, cooling, and ventilation, accounts for most of the energy needs in homes and buildings. Other needs for energy in homes and buildings are lights, hot water, and diverse appliances and equipment (refrigerators, washing machines, stoves, ovens, microwaves, TVs, computers, etc.).

Consumers are key players in this context, as demand flexibility is crucial to cope with the intermittency of most renewable energy sources, such as wind and sun. Demanding active participation is particularly important to ensure the efficient use of available energy at local and global levels.

This Special Issue, "Sustainable Energy Consumption", addresses the different perspectives of energy demand and use, commonly referred as energy consumption, for ensuring energy sustainability, increased energy efficiency, and reasonable energy costs.

This Special Issue includes five papers [1-5]. Energy sustainability is a key challenge for a developed and sustainable world. The use of renewable energy has significantly increased over the past few years, bringing new technical and business challenges to the energy sector.

The paper of Sakuma and Nishi proposes a thermal performance assessment solution for residential housing [1]. This work is focused on the trends of smart home and house energy management systems. The proposed method enables the assessment of the existing conditions of residential housings. The proposed solution hardware involves a monitoring system of power meters for air conditioners and thermometers and a Bluetooth low-energy beacon. The interaction with the proposed solution can be conducted through a smartphone application. Simulation and experimental data are combined, and analyses of estimation errors and accuracy are performed. Assessments of the experimental data show that the proposed method achieved the average transmission heat transfer coefficient value estimations using a low-cost system.

The huge amount of data we need to store, analyze, and protect originated data centers, buildings to house computer systems and associated equipment with redundant and backup components, and infrastructure for power supply to feed computing and cooling devices. Thus, energy efficiency is a very important request for data centers since the energy needs of a data center is sometimes equivalent to the total energy use of a small town. Additionally, there is the need to consider data centers' carbon footprint and impact on the environment. Renewable energy solutions are being used in data centers to cope with these constraints. The paper of Li, Wang, Luo, and Pan proposes a thermalaware workload management method to maximize the utilization of renewable energy sources in data centers, considering the power consumption of computing and cooling 
systems [2]. The proposed method uses the concept of workload shifting to schedule more delay-tolerant workloads and allocate resources in the data center according to the availability of renewable energy supply and the variation of cooling temperature. Simulation experiments have been performed using the Cloudsim-plus platform and demonstrated that the proposed method could effectively reduce the consumption of brown energy and maximize the use of renewable energy.

Photovoltaic cells convert sunlight into electricity. When grouped in a framework, photovoltaic cells constitute photovoltaic (PV) or solar panels. PV panels are a good way to generate renewable energy, allowing a distributed solution to produce "green" energy and reduce carbon footprint and environmental impact. Usually placed on building roofs or other places for decentralized use, they can be mounted to create photovoltaic power stations as well, allowing the use of photovoltaic systems at the utility level. More recently, there has been a trend to place these photovoltaic power stations on water, such as on artificial lakes. Cao, MO Esangbedo, Bai, and CO Esangbedo propose a multicriteria decision-making approach for contractor selection for installing solar panel energy systems [3], presenting a case study of a floating solar panel energy system installation. A combination of stepwise weight analysis ratio assessment with full, consistent method weights used with grey relational analysis (GRA) corresponds to the new hybrid method proposed by the authors, and the evaluation is based on the distance from average solution methods. The used approach increases decision makers' confidence in awarding the installation of solar panel energy systems to the top-ranked contractor.

The importance of renewable energy resources, such as solar and wind, has impacted the generation and modified how electricity is produced and distributed. Since the possibility of production is available in many places, distributed generation has gained increased importance. In this scenario, new ways to operate in the electricity market have appeared, and entities such as virtual power players, a kind of aggregator in the coordination of small energy resources, have started to make sense. The energy produced by photovoltaic panels or wind turbines varies according to weather conditions, being much more unpredictable than traditional hydroelectrical and thermoelectrical generation. Thus, energy use patterns may adapt to a power system's needs to benefit from price variations in electricity. Demand response refers to an adaptation in the consumer's energy usage to the needs from the supply side. Silva, Faria, and Vale [4] propose coordinated management of small resources through a virtual power player and participation in the wholesale electricity market as an intermediary in transactions with an independent system operator. With the communication of this aggregator with small resources, a better clustering approach to creating resource clusters, and the use of a dynamic remuneration tariff, the authors propose that a new classification phase be joined to the scheduling phase of energy usage. In this way, virtual power players will operate more efficiently and fairly in the electricity market.

Energy performance contracting is defined as a mechanism for organizing energy efficiency financing. At the urban scale, an energy service company provides a set of services to obtain energy savings and remunerates consumers who achieve energy savings. This is usual with the public sector and is also emerging in commercial buildings and industrial plants. The goal of Zhang and Yuan is to identify future research trends in energy performance contracting through an extensive analysis of 127 journal papers published from 2008 to 2018 [5]. Energy performance contracting focused on five main topics in the last decade. These five topics are the implementation of energy performance contracting projects, the mechanism and business models, the decision-making process, the energy service companies involved in the projects, and the risk management in energy-performance-contracting projects. The selection of target scholarly papers started with 1743 papers from the web of science (WoS) in which energy performance contracting topics are referred. Conference papers were not considered, and the main focus of energy performance contracting was searched, resulting in the 127 selected papers. Most of the analyzed papers have been published in the last 4 years. Eleven future directions for energy performance contracting are identified and discussed in the paper. 
These five papers constitute a good and diverse overview of sustainable energy usage research area and are of interest for all researchers in the field, namely, for those motivated to propose new methods and technologies for future years.

Funding: This research received no external funding.

Conflicts of Interest: The authors declare no conflict of interest.

\section{References}

1. Sakuma, Y.; Nishi, H. Estimation of Building Thermal Performance using Simple Sensors and Air Conditioners. Energies 2019, 12, 2950. [CrossRef]

2. Li, Y.; Wang, X.; Luo, P.; Pan, Q. Thermal-Aware Hybrid Workload Management in a Green Datacenter towards Renewable Energy Utilization. Energies 2019, 12, 1494. [CrossRef]

3. Cao, Q.; Esangbedo, M.O.; Bai, S.; Esangbedo, C.O. Grey SWARA-FUCOM Weighting Method for Contractor Selection MCDM Problem: A Case Study of Floating Solar Panel Energy System Installation. Energies 2019, 12, 2481. [CrossRef]

4. Silva, C.; Faria, P.; Vale, Z. Demand Response and Distributed Generation Remuneration Approach Considering Planning and Operation Stages. Energies 2019, 12, 2721. [CrossRef]

5. Zhang, W.; Yuan, H. Promoting Energy Performance Contracting for Achieving Urban Sustainability: What is the Research Trend? Energies 2019, 12, 1443. [CrossRef] 